\title{
Fenômenos enunciativos e argumentação nas brochuras do Conselho Federal Suíço sobre as votações populares ${ }^{1,2}$
}

\author{
Phénomènes énonciatifs et argumentation dans les brochures \\ du Conseil Fédéral Suisse sur les votations populaires
}

\author{
Corinne Rossari
}

Université de Neuchâtel - Suisse $\diamond$

\begin{abstract}
Resumo: Nossa análise trata das brochuras enviadas aos cidadãos e cidadãs suíços por ocasião de votações populares. Essas brochuras se apresentam como tendo um alcance essencialmente pedagógico, dedicada a facilitar a escolha eleitoral do cidadão. Meu propósito é o de oôr em evidência os mecanismos estruturais e enunciativos que presidem a organização das informações e a sua discursivização. Será visto como essas brochuras chegam a conciliar o alcance pedagógico com um alcance persuasivo manifestado pela recomendação sistemática de voto com os quais se harmonizam.
\end{abstract}

Palavras-chave: Argumentação; Enunciação; Modalidade; Organização do discurso

Résumé: Notre analyse porte sur les brochures envoyées aux citoyen-ne-s suisses à l'occasion de votations populaires. Ces brochures se présentent comme ayant une visée essentiellement pédagogique, vouée à faciliter le choix électoral du citoyen. Mon propos est de mettre en évidence les mécanismes structurels et énonciatifs qui président à l'agencement des informations et à leur mise en discours. On verra comment ces brochures parviennent à concilier la visée pédagogique avec une visée persuasive manifestée par la recommandations systématique de vote dont elles sont assorties.

Mots-clés: Argumentation; Énonciation; Modalité; Organisation du discours

\section{Introdução}

Quando das votações populares, o Conselho Federal (a partir de agora $\mathrm{CF}$ ) edita brochuras explicativas enviadas a todos os cidadãos afim de informá-los sobre o que está em jogo do objeto submetido ao voto. Essas brochuras dizem respeito a um discurso político muito particular: elas devem aparecer como informativas, ou seja, explicar o texto submetido ao voto sem procurar orientar a escolha do cidadão e, ao mesmo tempo, elas devem permitir às autoridades defender sua posição. Como assinala Marc Bonhomme (neste mesmo número), essas brochuras são investidas de um duplo objetivo: "explicar o objeto do

\footnotetext{
1 Texto publicado em francês, em 10 de abril de 2013, pela revista suíça on line Argumentation et analyse de discours.

2 Tradução: Leci Borges Barbisan - PPGL/PUCRS, Porto Alegre, RS. Tradução e publicação autorizadas por Ruth Amossy, organizadora da revista suíça on-line Argumentation et analyse de discours.
}

voto e recomendar a posição do Conselho Federal". Apesar dessa recomendação, elas não devem aparecer como a etapa final da campanha dirigida pelo Conselho Federal com o objetivo de persuadir os eleitores sobre a legitimidade da reforma proposta ou dos perigos da iniciativa submetida ao voto. É essencial para a própria sobrevivência dessas brochuras, que elas apareçam como estando fora da campanha: toda indicação de qualquer caráter tendencioso arrisca ameaçar sua própria existência. Uma iniciativa que visa a fazer parar as atividades de comunicação desenvolvidas pelo CF dirigida aos cidadãos foi assim depositada em 2008. Essa iniciativa intitulada "Soberania do povo sem propaganda governamental", até mesmo se ela se referia especificamente à edição dessas brochuras, visava restringir as atividades de comunicação nas mídias do CF. Ela colocava, portanto, em perigo toda forma de comunicação das autoridades federais dirigidas aos cidadãos. 
O objetivo de meu artigo é o de descrever os mecanismos inerentes à estrutura e à enunciação que fazem aparecer ao mesmo tempo o que está em jogo do ponto de vista informativo e persuasivo próprio dessas brochuras. Numa primeira parte, eu descrevo a estrutura relativa à organização da brochura sublinhando o que permite conjugar informação e persuasão no modo de apresentação das informações dadas. Numa segunda parte, eu analiso o modo como os conteúdos são enunciados referindo a teoria da polifonia de Ducrot (1984, 1989) e de Carel (2011). Ver-se-á que o modo de enunciação dos conteúdos permite fazer aparecer um efeito de neutralidade da parte dos autores na origem desses conteúdos.

Minha análise se fundamenta sobre o texto da iniciativa popular "Para neutralizações democráticas". Adotei nesse estágio de minha pesquisa, um procedimento ascendente, razão pela qual eu limito meu objeto de estudo a uma análise de detalhes sobre o texto de uma única votação popular, combatida pelo CF. Ela oferece assim todo o dispositivo que permite conjugar os dois objetivos - informar e persuadir - potencialmente antagônicos próprios desse tipo particular de discurso político. É preciso, portanto, interpretar nosso corpus como um exemplar da prosa do $\mathrm{CF}$ e não como uma escolha induzida por um tema delicado no plano político.

\section{A organização de uma brochura}

A organização de uma brochura responde sempre ao mesmo esquema, independentemente do objeto particular de que trata. Essas brochuras são apresentadas de modo a pôr em evidência a vontade das autoridades sobre o objetivo informativo de sua comunicação. A intenção informativa dos autores é anunciada explicitamente na página de rosto de todas as brochuras. Trata-se da menção "Explicações do Conselho Federal" que intervém no alto à direita da página de título, logo abaixo da data da votação em questão. $\mathrm{O}$ alcance perlocutório de informação é tão bem colocado na apresentação que ela se torna uma forma de ato ilocutório fundamentado na equivalência seguinte: dizemos que informamos, portanto, informamos.

Esse alcance informativo é associado, sempre na própria apresentação da brochura, com alcance persuasivo assumido. A brochura comunica, após a apresentação dos objetos submetidos ao voto e o sumário, uma recomendação de voto em negrito sobre cada objeto. Esta intervém no início (antes da exposição do objeto) e no fim (a recomendação encerra a parte intitulada "Os argumentos do CF). Esse último enunciado de recomendação é apresentado pela expressão anafórica "Por todas essas razões" como fundamentado sobre os argumentos evocados em cada parte. Ele permite assim motivar, de modo retroativo, a primeira recomendação.

O desafio que faz aparecer a apresentação dessas brochuras é, portanto, o de assumir uma postura de persuasão, pondo em destaque um alcance pedagógico, para que a tomada de posição não se torne o objetivo primeiro da brochura.

\subsection{A página de título}

Votação popular de $1^{\circ}$ de junho de 2008

Explicações do Conselho Federal

1 Iniciativa popular "para naturalizações democráticas"

2 Iniciativa popular "Soberania do povo sem propaganda governamental"

3 Artigo constitucional "Qualidade econômica no seguro doença" (contraprojeto à iniciativa popular "Para a redução dos prêmios de seguro doença no seguro de base" que foi retirada) ${ }^{3}$

A página de título, que se apresenta sempre segundo o mesmo esquema, dá como indicação a fonte, a saber, em termos ducrotianos, o sujeito falante das brochuras, na

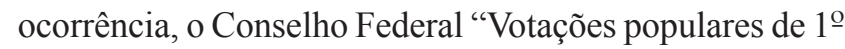
de junho de 2008, Explicações do Conselho Federal. O título ao explicitar o objetivo perlocutório da brochura explicar ao cidadão o conteúdo dos objetos submetidos ao voto - inscreve o texto de imediato num gênero definido: o discurso pedagógico. Isso supõe papeis precisos a serem atribuídos às instâncias emissora e receptora, a saber o papel de pedagogo, de formador para a instância emissora e o de "aluno-cidadão" para a instância receptora. O alcance global de informação é assim construído sobre a base de uma troca unilateral no quadro do qual uma instância divulga seus conhecimentos sobre um objeto a uma coletividade. Os conhecimentos dispensados são apresentados como explicações.

\subsection{0 sumário}

A primeira página dessas brochuras apresenta um sumário parcial das matérias, bem como um resumo sobre o conteúdo dos objetos submetidos ao voto.

\section{Sobre o quê se vota? \\ Iniciativa popular "Para naturalizações demo- cráticas" (Primeiro objeto) \\ A obtenção do direito de cidade comunal é uma primeira etapa importante para a aquisição do passaporte suíço. A inciativa vista a dar às comunas}

\footnotetext{
3 Página de título votação popular de 1 o de junho de $2008<\mathrm{http} / / / /$ www.bk.admin.ch/themen/pore/va/20080601/index.html?lang=fr\# sprungmarke_1_3>.
} 
o poder de fixar de modo autônomo o procedimento e o órgão competente para a outorga do direito de cidade comunal. Além disso, as decisões populares em matéria de naturalização seriam definitivas e assim não poderiam mais ser objeto de um recurso diante de um tribunal. A inciativa foi lançada em reação a dois decretos do Tribunal Federal, datados de 2003, que obrigavam as comunas a adotar procedimentos conformes aos princípios do Estado de direito e incluindo um direito de recurso.

Explicações

Texto submetido ao voto

páginas 5-15

página 12

Iniciativa popular "Soberania do povo sem propaganda governamental" (Segundo objeto)

A iniciativa popular "Soberania do povo sem propaganda governamental" exige a restrição das atividades de informação da Confederação antes das votações. O Conselho Federal e o Parlamento propõem rejeitar essa iniciativa, porque explicações objetivas e equilibradas, fornecidas pelo Conselho Federal, fazem igualmente parte do debate público em torno de um objeto posto em votação.

Explicações

páginas $17-27$

Texto submetido ao voto páginas $23-24$

Artigo constitucional "Qualidade e eficiência econômica no seguro-doença" (Terceiro objeto)

(contraprojeto de iniciativa popular "Para a diminuição dos prêmios de seguro-doença no seguro de base, que foi retirada)

O Parlamento elaborou um contraprojeto de iniciativa popular "Para a baixa dos prêmios de segurodoença no seguro de base". Desde que a inciativa foi retirada, o povo e os cantões não votarão mais a não ser sobre esse contraprojeto.

Explicações

páginas 29-38

Texto submetido ao voto páginas $34-35^{3}$

O sumário distingue a parte "explicativa" intitulada "Explicações" da parte legislativa intitulada "Texto submetido ao voto". Na disposição efetiva desenvolvida nas brochuras, a parte "Texto submetido ao voto" é incluída na parte "Explicações”. A organização facilita, assim, a inferência segundo a qual a parte explicativa diz respeito ao texto submetido ao voto. Essa inferência dá legitimidade ao gênero pedagógico reivindicado pelo título das brochuras: é legítimo explicar a não especialistas que são os cidadãos, o conteúdo de um texto de lei.

\subsection{As partes}

No interior das brochuras, as subdivisões são mais complexas do que deixa pressagiar o sumário. No objeto "Para naturalizações democráticas", contam-se sete subdivisões.
A primeira é uma nova página de título que reitera o nome da iniciativa e que formula a pergunta sob forma de discurso direto à qual o cidadão deve responder significando-lhe por um metadiscurso, que precede essa pergunta, à qual ele deve responder. Isso atesta o objetivo explicativo da brochura. Segue uma intervenção que toma o lugar da intervenção reativa de resposta suscitada pela pergunta. Essa intervenção, embora formalmente integrada na troca ${ }^{5}$ aberta pela intervenção de pergunta (ela lhe é adjacente), apresenta um conteúdo que é exterior a essa troca. Ela contém dois enunciados: um enunciado que consiste em um ato de recomendação que especifica a resposta que o cidadão deve dar à pergunta que lhe é colocada e um enunciado que descreve os resultados do voto junto ao conselho nacional e ao conselho dos Estados. Essa intervenção é ao mesmo tempo deslocada em relação à intervenção de pergunta e, ao mesmo tempo, ela toma o lugar da intervenção reativa que deve ser produzida pelo cidadão na sequência da pergunta que lhe é colocada. O lugar no qual se situa o enunciado de recomendação manifesta o alcance persuasivo da brochura. Como destacado acima, ele é colocado em negrito e retroativamente motivado pelos elementos mencionados na parte $O s$ argumentos do $C F$. O objetivo explicativo da brochura se vê, então, de fato, subordinado a um objetivo persuasivo.

\section{Primeiro objeto \\ Iniciativa popular \\ "Por naturalizações democráticas" \\ A pergunta à qual você deve responder é a seguinte: \\ Você aceita a iniciativa popular "Para natura- lizações democráticas?" \\ O Conselho Federal e o Parlamento lhe reco- mendam rejeitar a iniciativa \\ O Conselho Nacional rejeitou a iniciativa por 127 votos contra 67, sem abstenção, o Conselho dos Estados por 34 votos contra 7 e 2 abstenções. ${ }^{6}$}

O resto da brochura é organizado em seis partes apresentadas no mesmo plano. Os títulos são:

- O essencial resumidamente

- O objeto em detalhe

- Como alguém se torna suíço? (quadro que faz parte de "O objeto em detalhe")

\footnotetext{
4 Página 3 votação popular de 01 de junho de $2008<$ http://www.bk.admin $\mathrm{ch} /$ themen/pore/va/20080601/index.html?lang=fr\#sprungmarke $13>$.

5 Anoção de troca é utilizada de acordo com o sentido formal dado na última versão do modelo genebrino da organização do discurso (ROULET et al., 2001). Esse modelo preconiza uma concepção hierárquica do discurso, segundo a qual a troca é caracterizada por constituintes - as intervenções - (no máximo duas) reunidos pelas relações de interdependência: "Um não pode existir sem o outro" (2001, p. 54 e seg.).

6 Página 5 votação popular de 01 de junho de $2008<$ http://www.bk.admin. $\mathrm{ch} /$ themen/pore/va/20080601/index.html?lang=fr\#sprungmarke_1_3>.
} 
- Texto submetido ao voto (parte anunciada no sumário como sendo diferente, mas compreendida na parte "Explicações")

- Os argumentos do comitê de iniciativa (parte apresentada no sumário como integrada à parte "Explicações")

- Os argumentos do Conselho Federal (apresentados no sumário como integrados à parte "Explicações").

Essas seções respondem a uma preocupação pedagógica de exaustividade. O texto submetido ao voto é precedido de partes que correspondem a uma análise macro (O essencial em resumo) e uma análise micro ( $\mathrm{O}$ objeto em detalhe) do objeto. Uma terceira parte (Como tornarse Suíço) compreende uma informação de plano de fundo sobre um ponto julgado essencial pelo CF para compreender o que está em questão no texto submetido ao voto. Depois a parte dedicada ao próprio objeto (Texto submetido ao voto), seguida de duas partes denominadas argumentativas representando as duas posições antagonistas. A sequência dessas duas seções, que apresentam os argumentos que emanam das duas partes, pode assim ser entendida como constitutiva do objetivo explicativo, como dá a entender o sumário (cf. inclusão das duas seções argumentativas na macro-seção "Explicações").

Assim apresentadas, essas seis seções reúnem todos os elementos necessários ao cidadão para que ele possa se pronunciar com todo conhecimento de causa. O esforço pedagógico prossegue na apresentação do texto inerente a cada seção.

Cada uma é subdividida em vários parágrafos associados a textos em epígrafe fazendo o papel de sínteses (mas também, em outras brochuras, de subtítulos). Esses textos em epígrafe permitem guiar a leitura do cidadão em função do que deveria idealmente ser retido. Eles exploram o mecanismo de leitura em diagonal para que sejam selecionados os pontos que devem reter a atenção do cidadão. Observar-se-á que são as mesmas temáticas que intervêm nessas epígrafes, na seção "O objeto em detalhe" e a seção "Os argumentos do CF". Por exemplo, na parte "O objeto em detalhe" destaca-se: "Procedimentos de naturalização corretos" (8) e na parte "Os argumentos do CF": "Procedimentos conformes aos princípios do Estado de direito, mas não de direito à naturalização" (15).

\section{O objeto em detalhe}

\section{Jurisprudência do Tribunal Federal}

O lançamento da iniciativa está ligado a decisões de naturalização controvertidas, tomadas quando de votações populares: em 2000, os cidadãos de uma comuna de Lucerne tinham recusado um número importante de pedidos de naturalização, só aceitando aqueles que emanavam de candidatos originários de países próximos. As pessoas lesadas dirigiram-se então ao Tribunal Federal que admitiu o recurso e anulou as recusas de 9 julho de 2003. No mesmo dia, o Tribunal Federal também se pronunciou sobre a validade de uma iniciativa que exigia das naturalizações pelas urnas na cidade de Zurich. Ele constata que as naturalizações pelas urnas são fundamentalmente contrárias ao direito, porque as decisões não devem ser motivadas nesse tipo de procedimentos.

\section{Procedimentos de naturalização corretos}

O Tribunal Federal é de opinião que os organismos competentes têm também, de modo semelhante ao de outras autoridades no exercício de suas funções, de respeitar disposições jurídicas restritivas quando de decisões de naturalização. Um pedido de naturalização não pode, portanto, ser recusado - como pode, por exemplo, se produzir quando da naturalização pelas urnas - por motivos subjetivos ou dificilmente explicáveis, o que seria o caso se pedidos fossem recusados só pelo motivo de que os nomes dos candidatos traíssem suas origens. ${ }^{7}$

\section{Os argumentos do Consellho Federal}

A iniciativa "Para naturalizações democráticas" se acomoda à ideia de que nossos valores fundamentais não se aplicam em toda parte e a todos. A supressão exigida da interdição da discriminação e do arbitrário quando das naturalizações é contrária aos princípios do Estado de direito moderno. A aceitação da iniciativa tornaria caducos, em numerosos cantões, procedimentos eficazes e introduzidos democraticamente. O Conselho Federal rejeita a iniciativa em particular pelos seguintes motivos:

\section{Evitar a discriminação do arbitrário}

O Conselho Federal considera que os candidatos à naturalização têm direito a procedimentos corretos e que as autoridades competentes em matéria de naturalização devem imperiosamente respeitar os direitos fundamentais, principalmente a interdição da discriminação e do arbitrário. Toda pessoa que deseja se fazer naturalizar, com todos os direitos e os deveres que isso implica, deve poder contar com um tratamento correto e transparente de seu pedido no nível comunal.

\section{Legitimidade democrática das decisões de natu- ralização \\ O título de iniciativa popular dá a entender que só as naturalizações pelas urnas são democráticas. Ora, os cantões decidem, segundo regras democráticas, qual órgão pode proceder às naturalizações, por exemplo, a assembleia burguesa ou um conselho de naturalização democraticamente eleito. ${ }^{8}$}

\footnotetext{
7 Página 8 Votação popular de $1^{\circ}$ de junho de $2008<$ http//www.bk.admin $\mathrm{ch} /$ themen/pore/va/20080601/index,html?lang=fr\#sprungmarke $13>$.

8 Página 14 votação popular de $1^{\circ}$ de junho de $2008<$ http://www.bk.admin. $\mathrm{ch} /$ themen/pore/va/20080601/index.html?lang=fr\#aprungmarke_1>.
} 
Procedimentos conformes aos princípios do Estado de direito, mas não de direito à naturalização

Uma democracia forte tem necessidade de um Estado de direito que garanta procedimentos corretos a todos os habitantes. O órgão competente é hoje já livre para recusar pedidos de naturalização, com a condição de motivá-los objetivamente - por exemplo sublinhando uma falta de integração. São ilícitas unicamente as recusas discriminatórias e arbitrárias, por exemplo, a recusa de todos os pedidos depositados por pessoas originárias de um país particular, portando patronímicos particulares, pertencendo a uma religião particular ou cuja pele é de uma cor particular. O direito federal não concede direito à naturalização.

\section{Preservar a estrutura federalista}

Segundo o direito em vigor, as comunas só gozam de autonomia se o direito cantonal dispõe assim. A iniciativa quebra essa estrutura federalista que mostrou seu valor e retira dos cantões a competência de parar os procedimentos de naturalização no nível comunal. Resultaria disso uma grande quantidade de procedimentos e de competências em matéria de naturalização. Essa atomização do direito poderia, como no passado, conduzir a um "turismo das naturalizações" indesejável, que não estaria no interesse das comunas, nem no dos cidadãos. A iniciativa é contrária à prática atual e ao direito constitucional de numerosos cantões.

\section{Garantir os direitos fundamentais}

A interdição de um direito de recurso contra decisões de naturalização discriminatórias exigidas pela iniciativa é contrária às obrigações internacionais da Suíça e esvazia a Constituição de sua substância. A Constituição Federal garante de fato a toda pessoa a possibilidade de recorrer em caso de violação de seus direitos e a protege principalmente contra discriminações pelo fato de sua origem.

Por todas essas razões. O Conselho federal e o Parlamento recomendam rejeitar a iniciativa popular "Por naturalizações democráticas". 8

Em resumo, a organização efetiva (que se descobre pela leitura das brochuras) assume os dois objetivos (explicar e recomendar) compreendendo seções "explicativas" e "argumentativas". A organização enunciada pelo sumário mascara as partes "argumentativas" integrandoas na macroparte explicativa. O lugar estratégico no qual intervém por duas vezes o enunciado de recomendação põe finalmente $o$ alcance explicativo a serviço do alcance persuasivo. Desenha-se, portanto, uma tensão entre os dois alcances no próprio dispositivo utilizado para apresentar o conteúdo das brochuras.

Vamos ver agora como se manifesta essa dupla restrição nas escolhas enunciativas que caracterizam os conteúdos dos enunciados constitutivos das diferentes partes e subpartes dessas brochuras.

\section{Os procedimentos enunciativos e a noção de "neutralidade"}

Qual dispositivo enunciativo é posto para que o texto das brochuras apareça ao cidadão como "objetivo", "neutro" e quais instrumentos pragmáticos permitem envolver essa noção de neutralidade? Minha abordagem é fundamentada sobre os índices enunciativos constitutivos do sentido do enunciado. Para identificá-los, vou explorar três teorias: a teoria da polifonia ducrotiana, a teoria argumentativa da polifonia - chamada TAP - de Marion Carel e as teorias que apelam para a noção de evidencialidade - centrada na marca da fonte de uma informação na língua (ver as referências infra). Essas três correntes permitem identificar a posição do locutor no quadro de uma semântica do enunciado. $\mathrm{O}$ dispositivo enunciativo é visto aí como parte integrante da significação linguística. A escolha de utilizar uma forma em vez de outra poderá ser interpretada como assumindo o modo como o locutor modula sua atitude.

\subsection{Ferramentas para caracterizar 0 dispositivo enunciativo do conjunto da brochura}

Para descrever o dispositivo enunciativo no conjunto das brochuras, as noções de "sujeito falante" e de locutor, tais como elas são definidas pela teoria da polifonia de Ducrot (1984 e 1989) são suficientes:

- Todo enunciado tem uma fabricante: o sujeito falante.

- A todo enunciado se atribui um autor que é chamado locutor.

$\mathrm{Eu}$ acrescento a esse binômio uma terceira regra seguindo as observações de Carel (no prelo) sobre a presença do interlocutor enquanto elemento constitutivo do sentido do enunciado:

- A todo enunciado pode-se atribuir, ou não, um destinatário que é dito alocutário. ${ }^{10}$

Para ilustrar a distinção entre "sujeito falante" e "locutor", eu retomo o exemplo comentado por Carel (2011, p. 300): "Gislebertus hoc fecit", enunciado gravado pelo próprio no tímpano da catedral de Autun. Esse enunciado se atribui um locutor distinto do sujeito falante. O sujeito falante é Gislebertus. O enunciado fala na terceira pessoa desse último. Ele se atribui assim um autor - o

\footnotetext{
9 Página 15 - votação popular de 01 de junho de $2008<$ http://.bk.admin. ch/themen/pore/va.20080601/index.html?lang=fr\#sprungmarke $13>$.

${ }^{10} \mathrm{Eu}$ remeto a Carel (no prelo) para uma análise detalhada das instâncias receptoras. Utilizarei, quanto a mim, dois termos para designar essas instâncias: o de "alocutário" para designar a instância receptora inscrita no sentido do enunciado e o de "destinatário" para recobrir toda instância suscetível de se sentir concernida pelo conteúdo comunicado.
} 
locutor - que, com isso, não tem identidade própria. Ele é apenas distinto do sujeito falante. Esse locutor, para retomar a fórmula de Carel, não é assim implicado "na glória" (sic) do personagem (sujeito falante) de quem ele fala. Ele fica fora dos fatos relatados, que dizem respeito exclusivamente ao sujeito falante.

As brochuras do CF manifestam duas tendências antagonistas na construção de seu locutor. As três primeiras páginas dessas brochuras dão indicações que mostram que seus enunciados se atribuem um locutor potencialmente incarnado por um Nós. De um lado, o texto da terceira página da capa (cf. o fac-simile reproduzido em 1.3) dirige-se de modo direto a um destinatário (por meio do pronome "você"). Cf. "A pergunta à qual você deve responder..."; "O conselho Federal e o Parlamento recomendam a você rejeitar a iniciativa" (eu sublinhei). Esses enunciados pressupõem assim um Nós pelo uso do dêitico "você". Mas, por outro lado, o Nós não intervém nunca no texto. $\mathrm{O}$ ato de recomendação é formulado na terceira pessoa (o que lhe faz perder sua performatividade). Estamos, portanto, diante de um caso semelhante ao de Gislebertus, com a diferença de que esses enunciados se atribuem um locutor pelo recurso ao dêitico de segunda pessoa. Eles permitem assim ao mesmo tempo desimplicar a instância CF (que é o referente do sujeito falante) no ato de recomendação feito ao cidadão e tornar a instância locutor presente, mas não identificável, já que apresentada unicamente como distinta do sujeito falante.

Esse dispositivo põe em destaque um primeiro efeito de neutralidade. A identidade da instância responsável pelos conteúdos permanece mascarada. Os conteúdos são então percebidos como se impondo por eles mesmos. Nisso, sua enunciação não pede reação de parte do destinatário. Embora o enunciado citado supra se atribua por meio de Você um alocutário, esse alocutário não saberia, sempre de acordo com o conteúdo do enunciado em questão, reagir, considerando-se que a voz do locutor permanece não identificável. Se o ato de recomendação tivesse sido proferido na primeira pessoa: "Nós lhe recomendamos que...", não haveria essa dualidade. Tratar-se-ia de um conteúdo cuja responsabilidade é de atribuir ao $\mathrm{CF}$ e que comunica um ato de recomendação por meio de uma fórmula performativa. Ele construiria assim ipso facto um alocutário enquanto instância suscetível de reagir. $\mathrm{O}$ dispositivo escolhido - que minimiza a reatividade do destinatário ${ }^{11}$ - é igualmente possível nas escolhas enunciativas que caracterizam os enunciados que compõem as brochuras.

\footnotetext{
$\overline{11}$ Eu utilizo intencionalmente a palavra "destinatário".
}

\subsection{Ferramentas para caracterizar o dispositivo enunciativo dos enunciados das brochuras}

Para caracterizar esse dispositivo, eu me inspiro livremente nas ferramentas da Teoria Argumentativa da Polifonia (TAP), tais como são expostas em Carel (2011, p. 289 e seguintes) e nos trabalhos que trazem a marca da origem do saber - ver Dendale e Tasmowski $(1994,2001)$ para uma introdução nesse contexto. As ferramentas preconizadas por Carel permitem distinguir, segundo três parâmetros, o modo como um conteúdo é introduzido:

1. o modo de aparecimento de um conteúdo no interior de um discurso;

2. a voz pela qual um conteúdo é comunicado;

3. a implicação do locutor na concepção do conteúdo do enunciado.

1. Segundo a TAP, um conteúdo é "plenamente comunicado" se ele é apresentado como sendo o centro do discurso em desenvolvimento; ele é "acordado", se ele está fora do centro, ou ainda se ele é "excluído", se ele é recusado por um morfema de negação. Por exemplo, em uma estrutura "X disse que $\mathrm{P}$ ", pode-se comunicar plenamente "P" - nesse caso, "X disse que P" é acordado - ou comunicar plenamente "X disse que P". Segundo essa última interpretação, o fato de que foi $\mathrm{X}$ quem disse $\mathrm{P}$ tem uma incidência sobre $\mathrm{P}$, por exemplo tornando $\mathrm{P}$ mais válido ou menos válido. Há também a possibilidade de recusar um conteúdo que pode corresponder a negações chamadas polêmicas no contexto da polifonia ducrotiana. Por exemplo, o enunciado "não, não faz bom tempo" exclui comunicar "faz bom tempo" e esse conteúdo é interpretado como tendo sido comunicado por uma outra instância.

2. Um conteúdo pode ser apresentado como garantido por diferentes vozes. É necessário precisar a esse respeito que, se todo enunciado se atribui um autor (chamado locutor), isso não quer dizer que é esse autor que garante o conteúdo do enunciado. Eu mantenho três garantias diferentes. Um conteúdo pode ser apresentado como garantia pela voz do locutor. Por exemplo, o conteúdo "Léo é pouco inteligente" no enunciado "Eu acho Léo pouco inteligente" é apresentado por "eu acho" como garantia para a voz do locutor. Ele pode ser apresentado como garantia pela voz dos fatos. Nesse caso, os fatos são apresentados como falando por si mesmos. É o caso do enunciado "A terra é redonda". Enfim, o mesmo conteúdo "A terra gira" é apresentado como garantia para uma não-voz no enunciado "Parece que a terra gira". Por meio de "parece que", o locutor comunica (a terra gira), mas no contexto evidencial, pode-se dizer que ele recusa atribuir a P uma garantia (cf. ROSSARI, 2012, p. 79). 
3. Um conteúdo pode ser apresentado como implicando mais ou menos o locutor. É preciso diferenciar (2) de (3). O locutor pode ser apresentado pelo enunciado como implicado na concepção do conteúdo do enunciado ou como não implicado (como sendo um simples transmissor desse conteúdo) e isso independentemente da voz que garante o conteúdo. Para não tornar pesada a formulação, eu falarei de locutor implicado ou não implicado no conteúdo. No enunciado "Parece que infelizmente ninguém sobreviveu" "infelizmente" indica que o locutor está implicado na concepção do conteúdo (ninguém sobreviveu) e "parece que" indica que o conteúdo é garantido por uma não-voz.

Eu mantenho duas possibilidades para os parâmetros 1 e 3 respectivamente (plenamente comunicado vs não plenamente comunicado, e implicado vs não implicado). O parâmetro 2 , quanto a ele, dá a impressão de três possibilidades (voz L, voz Fatos, Não-voz). Obtém-se assim uma combinatória de doze possibilidades. Eu ilustro cada uma dessas possibilidades por um enunciado que utiliza uma cor para relacionar a interpretação ao índice nos casos em que não é evidente compreender sobre o que se fundamenta a categorização preconizada.

\begin{tabular}{|c|c|}
\hline $\begin{array}{l}\text { 1. Conteúdo apresentado como } \\
\text { plenamente comunicado, voz, } \\
\text { locutor, loc. implicado. Ex: Eu } \\
\text { acho essa lei injusta./Essa lei } \\
\text { é bem injusta./Essa lei parece } \\
\text { injusta. }\end{array}$ & $\begin{array}{l}\text { 2. Conteúdo apresentado como } \\
\text { plenamente comunicado, voz dos } \\
\text { fatos, loc. implicado. Ex: Essa } \\
\text { lei entrará em vigor somente em } \\
2012 \text { ! }\end{array}$ \\
\hline $\begin{array}{l}\text { 3. Conteúdo apresentado como } \\
\text { plenamente comunicado, não- } \\
\text { voz, loc. implicado. Ex: } \underline{A} \text { história } \\
\text { nos ensina o quanto a lei x é } \\
\text { injusta. }\end{array}$ & $\begin{array}{l}\text { 4. Conteúdo apresentado como } \\
\text { plenamente comunicado, voz } \\
\text { locutor, loc. não implicado. Ex: } \\
\text { Portanto a lei é injusta. }\end{array}$ \\
\hline $\begin{array}{l}\text { 5. Conteúdo apresentado como } \\
\text { plenamente comunicado, voz dos } \\
\text { fatos, loc. não implicado. Ex: Essa } \\
\text { lei entra em vigor em 2012./Essa } \\
\text { lei é escandalosa. }\end{array}$ & $\begin{array}{l}\text { 6. Conteúdo apresentado como } \\
\text { plenamente comunicado, não- } \\
\text { voz, loc. não implicado. Ex: } \\
\text { Parece que essa lei entra em } \\
\text { vigor em } 2012 \text {. }\end{array}$ \\
\hline $\begin{array}{l}\text { 7. Conteúdo [a lei é terrivelmente } \\
\text { injusta] apresentado como não } \\
\text { plenamente comunicado, voz } \\
\text { locutor, loc. implicado. Ex: Essa } \\
\text { lei, terrivelmente injusta, entrará } \\
\text { em vigor em } 2012 \text {. }\end{array}$ & $\begin{array}{l}\text { 8. Conteúdo [a lei entra em vigor } \\
\text { em 2012] apresentado como não } \\
\text { plenamente comunicado, voz dos } \\
\text { fatos, loc. implicado. Ex: Essa lei, } \\
\text { que entrará provavelmente em } \\
\text { vigor em 2012, é injusta. }\end{array}$ \\
\hline $\begin{array}{l}\text { 9. Conteúdo [a lei entra em vigor } \\
\text { em 2012] apresentado como não } \\
\text { plenamente comunicado, não- } \\
\text { voz, loc. implicado. Ex: Essa lei, } \\
\text { que é necessário que entre em } \\
\text { vigor em 2012, eu creio, é injusta. }\end{array}$ & $\begin{array}{l}\text { 10. Conteúdo [a lei entrará em } \\
\text { vigor em 2012] apresentado como } \\
\text { não plenamente comunicado, voz } \\
\text { locutor, loc. não implicado. Ex: } \\
\text { Essa lei, que entrará em vigor em } \\
2012 \text { é injusta, }\end{array}$ \\
\hline $\begin{array}{l}\text { 11. Conteúdo [o TF tem a pro- } \\
\text { priedade de estimar p] apre- } \\
\text { sentado como não plenamente } \\
\text { comunicado, voz dos fatos, } \\
\text { locutor não implicado. Ex: O TF } \\
\text { estima o recurso válido. }\end{array}$ & $\begin{array}{l}\text { 12. Conteúdo [o TF tem a pro- } \\
\text { priedade de estimar p] apresen- } \\
\text { tado como plenamente comuni- } \\
\text { cado, não-voz, loc. não implicado. } \\
\text { Ex: O TF deve necessariamente } \\
\text { estimar o recurso válido. }\end{array}$ \\
\hline
\end{tabular}

Observações: os parâmetros são fundamentados nos índices de enunciação, não no sentido das palavras empregadas. Assim, uma palavra dita subjetiva como discriminação, injustiça pode ser utilizada em enunciados cujo conteúdo é apresentado como resultante da voz dos fatos, ou como não implicando o locutor. Por exemplo, o enunciado "Que discriminação!" pode ser caracterizado assim: conteúdo plenamente comunicado, voz do locutor, loc. implicado. Em compensação, o enunciado "O direito das mulheres na Suíça antes de 1972 era discriminatório" corresponde à caracterização seguinte: conteúdo plenamente comunicado, voz dos fatos, loc. não implicado.

Essa combinatória permite caracterizar o modo como o conteúdo de um enunciado faz surgir a figura do alocutário. De fato, para que essa possa estar inscrita no enunciado, é necessário que o enunciado esteja relacionado ao caso 1 (conteúdo apresentado como plenamente comunicado, voz loc., loc. implicado). Se um único desses parâmetros não é realizado, então a figura do alocutário resulta mascarada. Expliquemo-nos. Para que haja a marca de um "endereço", o conteúdo deve ser apresentado como estando no centro do discurso em curso, portanto, plenamente comunicado. $\mathrm{O}$ destinatário não é suposto reagir aos conteúdos que estão fora do centro. É preciso também que o conteúdo seja garantido por uma voz identificável com a qual o destinatário possa interagir. Se o conteúdo é garantido por uma não-voz ou pela voz dos fatos, o destinatário não tem elementos para reagir. É preciso, enfim, que o locutor não apareça como o simples transmissor ou como aquele que só organiza um conteúdo em relação a outro (o que aparece pelo emprego dos conectores), mas que ele assinale de um modo ou de outro que ele está implicado na sua concepção. De novo, um locutor não implicado não é um interlocutor válido, e, portanto, não deixa elementos para uma reação do destinatário. Minha análise de alguns dos enunciados de nossa brochura fará aparecer diferentes meios de inibir a figura do alocutário, pelo fato de que um ou outro desses parâmetros não responde à configuração prevista para o caso 1.

\subsection{Escolha estratégica dos dispositivos enunciativos explorados}

O dispositivo enunciativo utilizado procura evitar o destinatário, mascarando a figura do alocutário (lembrando, a instância receptora que o enunciado se atribui). Evitando essa instância, ele minimiza o poder reativo suscitado pelos conteúdos comunicados. É assim que as brochuras conseguem dar-se um objetivo informativo neutro, apesar do ato de recomendação que é aí proferido. Os enunciados cujo alcance é puramente informativo, como aqueles que se encontram nos verbetes dos dicionários, por exemplo, não constroem a figura do 
alocutário. Eles não procuram solicitar reações. Eles se bastam a si mesmos. Os enunciados da brochura que nos serve de corpus têm a propriedade de mascarar a figura do alocutário, sem a qual toda possibilidade de diálogo fica inexplorável. Nos raros casos em que o dispositivo enunciativo é compatível com a construção de um alocutário, é o dispositivo enunciativo global que eu descrevi em 2.1 que a bloqueia, tornando a figura do locutor não identificável.

Como indiquei, os casos que são compatíveis com a figura do alocutário estão relacionados com a configuração ilustrada pelo $\mathrm{n}^{\mathrm{O}} 1$ de nosso quadro. O conteúdo é plenamente comunicado, ele é garantido pela voz do locutor, e o locutor é implicado no conteúdo. Alguns enunciados respondem a essa configuração.

(1) "A pergunta à qual você deve responder é a seguinte: Você aceita a iniciativa popular 'para naturalizações democráticas'? O Conselho Federal e o Parlamento the recomendam rejeitar a iniciativa" Extrato, p. 5.

(2) "Por todas essas razões, O Conselho Federal e o Parlamento the recomendam rejeitar a iniciativa popular 'Para naturalizações democráticas"'. Extrato, p. 15.

Esses enunciados estão entre os únicos que contêm um "nós" subentendido comportando um "você" explícito. Nisso, eles são aqueles que fazem mais aparecer a voz de L (ingrediente fundamental para que haja alocutário). Mas, de um lado, esses enunciados não comunicam conteúdo em jogo. Eles veiculam conteúdos que estão fora do que diz respeito ao próprio objeto da votação. Trata-se de enunciados que se referem ao caminho a seguir. Por outro lado, como se viu, a instância Locutor que eles supõem é desencarnada, na medida em que é não identificável.

Os enunciados situados na parte "Argumentos do CF" transmitem explicitamente a opinião do CF sobre o objeto submetido ao voto. Quanto a isso, se poderia esperar que eles fossem compatíveis com a construção da figura do alocutário. Mas, de novo, os procedimentos enunciativos escolhidos mascaram-na.

(3) "O Conselho Federal considera que os candidatos à naturalização têm direito a procedimentos corretos e que as autoridades competentes em matéria de naturalização devem imperativamente respeitar os direitos fundamentais, principalmente a proibição da discriminação e do arbitrário" Extrato, p. 14.

Nessa sequência, o sujeito falante (o CF) intervém como tema dos enunciados. Os enunciados transmitem a opinião do CF sobre o conteúdo. Nisso, há uma voz (a do $\mathrm{CF}$ ) responsável por essa opinião. $\mathrm{O}$ fato de que a opinião seja atribuída a uma voz identificada a torna propícia ao debate. Mas o dispositivo escolhido para introduzir essa opinião apaga a figura do alocutário.

O enunciado "O Conselho Federal considera que..." é ambíguo, segundo a análise preconizada por Carel e Ducrot (2009). Os autores se referem a uma observação da Lógica de Port-Royal (segunda parte, capítulo 8) sobre um enunciado da forma "X diz que P" (2009, p. 37) para pôr em relevo duas leituras próprias aos verbos de dizer, uma leitura chamada atributiva e uma leitura modal. Essas duas leituras se aplicam perfeitamente a nosso extrato.

$\mathrm{O}$ enunciado "O CF considera que p" permite: (a) uma leitura fundamentada no emprego atributivo de considerar, que corresponde a "O $\mathrm{CF}$ tem a propriedade de considerar que os candidatos... têm direito a...". Nesse caso, o enunciado diz alguma coisa a respeito das convicções do CF. A dimensão argumentativa dessa interpretação repousa num encadeamento fundamentado sobre o que Ducrot (1984) chama "raciocínio por autoridade". A paráfrase é: "O CF considera p, portanto p é verdadeiro". O dispositivo enunciativo ilustra então o caso 5: /parâmetro $1 /$ o conteúdo $O C F$ considera que $p$ é plenamente comunicado; /parâmetro $2 /$ o conteúdo é garantido pela voz dos fatos; / parâmetro 3/ o locutor é não implicado. $\mathrm{O}$ conteúdo $\mathrm{p}$ (os candidatos à naturalização têm direito a procedimentos corretos e as autoridades competentes em matéria de naturalização devem imperativamente respeitar os direitos fundamentais, principalmente a proibição da discriminação e do arbitrário), quanto a ele, é não plenamente comunicado, mas acordado. (b) $\mathrm{O}$ mesmo enunciado permite uma leitura fundamentada no emprego modal de considerar. Nesse caso, "O CF" é o ângulo de vista pelo qual o conteúdo $\mathrm{p}$ é modalizado. O locutor introduz $\mathrm{p}$ e o põe em perspectiva com o CF. A paráfrase corresponde a um contexto em segundo: "Segundo o $\mathrm{CF}$, os candidatos à naturalização têm direito a procedimentos corretos". A alusão ao CF é um modo de apresentar p. O CF é capaz de influenciar a interpretação a ser feita de p. Essa leitura é compatível com um encadeamento fundamentado sobre o que Ducrot (1984) chama de "autoridade polifônica": O $\mathrm{CF}$ diz que $\mathrm{p}$, portanto $\mathrm{q}$. Mas nesse caso, $\mathrm{p}$ não está por si mesmo em jogo no debate. Ele está fora do centro, Não é p (com o qual só se pode concordar) que é plenamente comunicado, mas q (se tivesse sido explicitado), que poderia corresponder a "é preciso rejeitar a iniciativa".

Nenhuma das duas leituras é compatível com a construção da figura de um alocutário. Esquematicamente, a dimensão argumentativa toma corpo ou por meio de um encadeamento fundamentado num raciocínio por autoridade: "É o CF que diz p DC p é verdadeiro" seja por meio de um encadeamento fundamentado numa autoridade polifônica: "Segundo CF, p, portanto 
q (= é preciso rejeitar a iniciativa)". Nos dois casos, o conteúdo que permitiria suscitar um debate (= é preciso rejeitar a iniciativa) e, portanto, por em relevo a figura do alocutário, não é comunicado.

Certos enunciados situados na parte "Explicações" relacionam-se igualmente com a configuração 1 e, nisso, deveriam ser propícias à construção da figura de um alocutário.

O conteúdo retirado do extrato seguinte deixa entrever amplamente a subjetividade da instância que é sua garantia, pelo uso de termos avaliativos.

(4) "Antes desses decretos do Tribunal Federal, o número de naturalizações pelas urnas era, entretanto, já muito fraco em relação ao número total de naturalizações.” Extrato p. 6-7 (ver anexo).

Essa sequência ilustra o caso 1: /parâmetro 1/ o conteúdo é apresentado como plenamente comunicado; /parâmetro 2/ ele é garantido pela voz do locutor; /parâmetro 3/ o locutor é implicado.

A apreciação sobre o número de naturalizações indica que é L que é a garantia do conteúdo. O uso do conector entretanto indica que o locutor manipula pontos de vista antagonistas, além de dispor dos conteúdos. Isso o faz aparecer como implicado na conceptualização desse conteúdo. Mas a construção da figura do alocutário chocase com o fato de que L não é uma instância incarnada no enunciado (não há nós nem você) e não é identificável.

$\mathrm{O}$ extrato que apresenta a iniciativa na página que serve de sumário deixa igualmente aparecer a instância L, sem, no entanto, fazer aparecer a figura do alocutário.

(5) “[...] A iniciativa visa dar às comunas o poder de fixar de modo autônomo e o procedimento, e o órgão competente para a concessão do direito de cidade comunal. Além disso, as decisões populares em matéria de naturalização seriam definitivas e não poderiam mais, assim, ser objeto de recurso diante de um tribunal. A iniciativa foi lançada em reação a dois decretos do Tribunal Federal, de 2003, que obrigavam as comunas a adotar procedimentos conformes aos princípios do Estado de direito e incluíam um direito de recurso." Extrato p. 3.

O verbo "visar" assinala uma interpretação do texto da iniciativa pelo locutor. Trata-se, portanto, da configuração 1 de nosso quadro. Mas a possibilidade de construção da figura do alocutário choca-se com o fato de que L não é uma instância incarnada no enunciado (não há nós nem você) e não é identificável. O conteúdo não é apresentado como devendo suscitar uma reação Olhemos a sequência seguinte: "Além disso, as decisões populares em matéria de neutralização seriam definitivas e não poderiam assim ser o objeto de um recurso diante de um tribunal". A possibilidade de situar o conteúdo em um mundo hipotético indica que é a voz de L que é a garantia disso. O uso do conector além disso vai no mesmo sentido, é o L que organiza os conteúdos. Mas, de modo semelhante ao caso precedente a construção da figura do alocutário choca-se com o fato de que L não é uma instância incarnada no enunciado (não há nós, nem você) e não é identificável. Não há L identificável, portanto, não há parceiro com quem dialogar. Passemos à análise da última sequência desse extrato, aquela cuja informação comunicada é a mais polêmica: "A iniciativa foi lançada em reação a dois decretos do Tribunal Federal, ambos de 2003, que obrigavam as comunas a adotar procedimentos conformes aos princípios do Estado de direito incluindo um direito de recurso". Dessa vez, é o próprio dispositivo enunciativo que torna esse enunciado não apto à construção da figura do alocutário. Trata-se do caso 11, segundo nosso quadro: /parâmetro 1/ o conteúdo é apresentado como não plenamente comunicado; /parâmetro 2/ ele é garantido pela voz dos fatos; /parâmetro 3/ o locutor é não implicado.

O conteúdo polêmico (Os decretos do TF obrigavam as comunas a adotar procedimentos conformes aos princípios do Estado de direito incluindo um direito de recurso) é um conteúdo de plano de fundo. Segundo a RST (cf. Mann e Thomson 1987), tratar-se-ia de um satélite de plano de fundo. É portanto assim colocado fora do campo do debate pelo próprio modo como o discurso é organizado. A relação retórica que une esse constituinte ao resto da sequência torna não pertinente a construção da figura do alocutário. Além disso, a presença de L é completamente apagada, na medida em que a garantia é apresentada como a voz dos fatos e o conteúdo não leva em conta nenhuma marca de implicação do locutor.

O conteúdo do mesmo modo altamente polêmico, retirado do extrato abaixo, é introduzido no discurso do mesmo modo.

(6) "Esse direito não é garantido no caso das naturalizações pela urnas, o que torna essa prática inconstitucional." Extrato 6 (ver anexo).

O conteúdo (prática inconstitucional) é um ataque $a d$ hominem em relação aos promotores da iniciativa: eles promovem uma iniciativa constitucional. $\mathrm{O}$ dispositivo enunciativo utilizado é aquele que mais permite evitar a construção da figura do alocutário. Ele está igualmente relacionado ao caso de 11 de nosso quadro. Segundo o parâmetro 1, o conteúdo (prática inconstitucional) não é plenamente comunicado, mas concedido. Ele é, portanto, obrigatoriamente apresentado como fora do campo da discussão. Segundo o parâmetro 2, ele é garantido pela 
voz dos fatos (não se tem acesso a uma interpretação segundo a qual a qualidade "inconstitucional" é uma interpretação do locutor). A sequência "o que torna essa prática inconstitucional" não poderia ser parafraseada por “A instância L julga essa prática constitucional”, mas por uma interpretação do tipo "É um fato: a prática é inconstitucional". Segundo o parâmetro 3 , o conteúdo não deixa aparecer nenhum vestígio da implicação do locutor. Todos os parâmetros inibem, portanto, a construção da figura do alocutário.

O extrato seguinte ilustra um caso em que o locutor é implicado no conteúdo, mas em que a figura do alocutário é mesmo assim apagada.

(7) "O Conselho Federal e o Parlamento rejeitam a iniciativa. Os procedimentos de naturalização devem respeitar os princípios do Estado de direito e não podem ser discriminatórios ou arbitrários." Extratos, p. 7 (ver anexo).

A primeira sequência desse extrato "O Conselho Federal e o Parlamento rejeitam a iniciativa" ilustra os dois casos de nosso quadro. Parâmetro 1: o conteúdo é plenamente comunicado; parâmetro 2: ele é garantido pela voz dos fatos; parâmetro 3; o locutor é implicado no conteúdo.

O fato de que o locutor é implicado na concepção do conteúdo, embora ele não seja a garantia desse conteúdo, se vê na justificativa que segue. Ter-se-ia aqui, portanto, um enunciado que poderia suscitar a construção de um alocutário ao qual a justificativa se dirige. Mas ao mesmo tempo, esse conteúdo é apresentado como estando sob a responsabilidade dos fatos e não de uma instância à qual é possível responder (o que seria o caso com um enunciado como: "nós rejeitamos a iniciativa"). A segunda sequência desse extrato "Os procedimentos de naturalização devem respeitar os princípios do Estado de direito e não podem ser discriminatórios ou arbitrários" ilustra ainda um caso de ataque ad hominem, mas é o conteúdo subentendido que o suporta. $\mathrm{O}$ ataque é veiculado pelo subentendido: "os promotores da iniciativa se acomodam com leis arbitrárias". O conteúdo plenamente comunicado evita a figura do locutor. Ele é garantido por uma não-voz, isto é, "voz da necessidade", e segundo o parâmetro 3, o locutor não é implicado na sua concepção.

Vejamos agora como é introduzido o contraprojeto defendido pelo CF.

(8) "O Conselho Federal e o Parlamento aprovam o contraprojeto indireto adotado pelas Câmaras federais em dezembro de 2007. Esse contraprojeto prevê que as assembleias comunais possam continuar a se pronunciar sobre os pedidos de naturalização. As recusas deverão, entretanto, ser motivadas antes do voto e não poderão ser discriminatórias." Extrato, p. 7 (ver anexo)
Analisemos a última frase desse extrato. Ela ilustra o caso 9: o conteúdo é plenamente comunicado, ele é garantido por uma não-voz, "voz da necessidade", e diferentemente da sequência analisada um pouco antes, o locutor é implicado. De fato, o uso de no entanto mostra um locutor que manipula pontos de vista antitéticos, e, portanto, implicado no que ele enuncia procurando agrupar seus adversários. Esse conteúdo é vetor de um novo ataque ad hominem contra os promotores da iniciativa. Mas esse ataque é de novo comunicado por um subentendido. Ele diz respeito às mesmas características: os promotores da iniciativa se acomodam com um texto de lei que pode ter consequências discriminatórias e arbitrárias. Ela é veiculada pelo conjunto complementar à aquele designado pelo predicado: "devem ser motivados" vs. "não devem ser motivados" (característica de arbitrário); "não poderão ser discriminatórios" vs. "podem ser discriminatórios" (característica de inconstitucionalidade). Não há, portanto, possibilidade de reação de parte de um destinatário, porque, de um lado, o conteúdo que veicula o ataque não é plenamente comunicado (ele o é por meio do subentendido, que pode ser reconstruído pela propriedade inversa àquela evocada pelo predicado) e, por outro lado, o conteúdo comunicado é garantido por uma não-voz, "voz da necessidade".

\subsection{Síntese da análise enunciativa}

Os ataques surgem, mas não são enunciados de modo a estar fora de todo debate. Três procedimentos podem ser levantados. Ou o conteúdo é enunciado segundo o dispositivo ilustrado pelo caso 1 do quadro, por exemplo, quando a instância responsável por um conteúdo comunicado é inscrita no enunciado pelo uso de dêiticos de segunda pessoa. Nesse caso, é o dispositivo enunciativo escolhido para o conjunto dos enunciados da brochura, que mascara a figura do alocutário, tornando a do locutor não identificável. Ou o conteúdo veicula um verdadeiro ataque ad hominem. Nesse caso, é o dispositivo enunciativo sobre sua introdução no discurso que o torna inapto ao debate. Ele pode não ser plenamente comunicado, cf. exemplo (6), ou ele é veiculado por um subentendido, cf. a segunda parte do exemplo (7). Enfim, quando o CF toma posição na parte reservada para essa finalidade sob a rubrica intitulada "Os argumentos de CF”, ele o faz não se expondo muito ao diálogo. Os encadeamentos de argumentos por autoridade ou de autoridade polifônica permitem mudar o que está verdadeiramente em jogo no debate, seja sobre um outro enunciado não explicitado -q (autoridade polifônica), seja sobre um conteúdo explícito $-\mathrm{p}$, mas que é introduzido como não plenamente comunicado (raciocínio por autoridade) - cf. análise do extrato (3). 


\section{Conclusão}

Apesar da recomendação explícita feita ao cidadão, vimos que o $\mathrm{CF}$ não pode se mostrar utilizando essas brochuras afim de aliar o cidadão ao seu ponto de vista. O objeto /o propósito das brochuras deve permanecer centrado na informação ao cidadão.

Esse objetivo é atingido, de um lado, pelo modo como as brochuras são organizadas, a saber, uma disposição que afirma o alcance pedagógico da brochura por meio dos títulos das partes e das explicações que rodeiam o texto de cada uma dessas partes, e, por outro lado, pelos dispositivos enunciativos desenvolvidos para introduzir a informação. Comunicando os conteúdos mais polêmicos de um modo que não permite reações, as brochuras preenchem o objetivo de aparecer como fora do debate político, como um esclarecimento sobre o que está em jogo na votação popular, e não como constituindo nelas mesmas um jogo para a escolha eleitoral a ser feita.

\section{Referências}

BONHOMME, Marc. Dialogisme et argumentation dans les brochures du Conseil Fédéral Suisse sur les votations populaires. Argumentation et analyse du discours, n. 10, 2013. Disponível em: $<$ http://aad.revues.org/1454>.
CAREL, Marion. Polyphonie argumentative et emprunt: le cas de il paraît que. (no prelo)

CAREL, Marion. L'entrelacement argumentatif. Paris: Champion, 2011.

CAREL, Marion; DUCROT, Oswald. Mise au point sur la polyphonie. Langue Française, Paris, n. 164, p. 33-44, 2009.

DENDALE, Patrick; TASMOWSKI, Liliane. L'évidentialité ou le marquage des sources du savoir. Langue Française, Paris, n. 102, p. 3-7, 1994.

DENDALE, Patrick; TASMOWSKI, Liliane. Evidentiality and related notions. Journal of Pragmatics, Amsterdam, v. 33, n. 3, p. 339-348, 2001.

DUCROT, Oswald. Le dire et le dit. Paris: Minuit, 1984.

DUCROT, Oswald. Logique, structure, énonciation. Paris: Minuit, 1989.

MANN, William; THOMPSON, Sandra. Rhetorical Structure Theory: toward a functional theory of text organization. Text\&Talk, Berlin, v. 8, n. 3, p. 243-281, 1988.

ROSSARI, Corinne. Valeur évidentielle et/ou modale de faut croire, on dirait et paraît. Langue Française, Paris, n. 173, p. 65-81, 2012.

ROULET, Eddy et al. Un modèle et un instrument d'analyse de l'organisation du discours. Berne: Peter Lang, 2001.

\section{ANEXO}

O essencial em resumo da votação "Para naturalizações democráticas", páginas 6 e 7.

\section{$O$ essencial em resumo}

Práticas atuais em matéria de naturalização

Os estrangeiros que desejam tornar-se Suíços devem preencher as condições fixadas pelo cantão de residência, a comuna de residência e a Confederação. O procedimento de naturalização é estipulado pelos cantões ou, se o direito cantonal assim o dispõe, pelas comunas. Não existe direito à naturalização, salvo se os cantões o prevêm expressamente. Os pedidos de naturalização recusados podem ser objeto de recurso diante de um tribunal, e até mesmo diante do Tribunal Federal em caso de agressões presumidas aos direitos fundamentais tais como a discriminação ou a violação do direito de ser ouvido.

Conteúdo da iniciativa popular

A iniciativa popular visa modificar essa organização das competências e pede

- que as comunas possam decidir de modo autônomo sobre que órgão é habilitado a conceder o direito de cidade comunal, e

- que as decisões desse órgão sejam definitivas e não possam, portanto, mais ser objeto de recurso.

O Tribunal federal fixa os limites

A iniciativa foi lançada como reação a dois decretos do Tribunal federal em 9 de julho de 2003. No primeiro caso, o Tribunal federal tinha qualificado como discriminatória a recusa de pedidos de naturalização em uma comuna de Lucerna e o havia anulado. No segundo caso, o Tribunal tinha confirmado a não validade de uma iniciativa que queria submeter, na cidade de Zurich, os pedidos de naturalização ao voto do povo. A Constituição Federal exige, para os candidatos cujo pedido de naturalização é negado, o direito de conhecer os motivos da recusa. Esse direito não é garantido no caso das naturalizações pelas urnas, o que torna essa prática inconstitucional. Os cantões concernidos, consequentemente, substituíram as naturalizações pelas urnas por outros procedimentos, principalmente por decisões de assembleias comunais, de parlamentos, de autoridades executivas ou de comissões de naturalização. Antes desses decretos do Tribunal federal, o número de naturalizações pelas urnas era, entretanto, já bastante fraco em relação ao número total de naturalizações. 
Posição do Conselho federal e do Parlamento

O Conselho Federal e o Parlamento rejeitam a iniciativa. Os procedimentos de naturalização devem respeitar os princípios do Estado de direito e não podem ser discriminatórios ou arbitrários. O Conselho federal e o Parlamento aprovam o contraprojeto indireto adotado pelas Câmaras federais em dezembro de 2007. Esse contraprojeto prevê que as assembleias comunais possam continuar a se pronunciar sobre os pedidos de naturalização. As recusas deverão, entretanto, ser motivadas antes do voto e não poderão ser discriminatórias.

Recebido: 30 de novembro de 2014

Aprovado: 26 de janeiro de 2015

Contato: corinne.rossari@unine.ch 